\title{
ADDRESSING THE NEGATIVE IMPACT OF CONSUMERISM ON YOUNG PEOPLE BY (RE)AWAKENING THEIR SPIRITUALITY THROUGH SENSE OF PLACE
}

\author{
K. Ontong \\ Department of Curriculum Studies \\ Stellenbosch University \\ Stellenbosch, South Africa \\ e-mail: krystle@sun.ac.za
}

\section{ABSTRACT}

Consumerism holds the view that personal wellbeing and happiness depend largely on the material goods a person can buy (Dwyer 2007). Advertising constantly bombards our youth with images of materially seductive things. The implied message given is that the right consumer goods will lead to a fulfilled life. However, the life experience of most young people is in stark contrast with what they should want as advocated by the consumption norms of society. It is often these contrasts that lead to feelings of inadequacy, lack of desirability and an inability to recognise one's own worth. I argue that one way of addressing these feelings among young people is by (re)awakening their spirituality, starting at school. However, spirituality in education is a potentially contested terrain and educators tend to shy away from it (De Klerk-Luttig 2008). I therefore suggest sense of place as an avenue for reawakening students' spirituality. I draw on the works of spirituality by Kessler (2000) and Webster (2004) and sense of place by Ardoin, Shuh, and Gould (2012) to provide a renewed, integrated framework.

Keywords: spirituality, place, sense of place, pedagogy, education, consumerism, advertising

"Young people who thrive have encountered deep connection. Moments of deep connection to the self - when we really know ourselves, express our true self, feel connected to the essence of who we are - nourish the human spirit ... Suffering trail the lives of those who are without such connections” (Kessler 2000, 20).

\section{INTRODUCTION}

Globalisation has drastically, and irreversibly, changed the ways in which people operate in the world from how they consume, work, play, collect data, process information and define their identity (Little 2000; Stromquist and Monkman 2000). Advertising is everywhere, and some educational news programmes contain intensive advertisements directed at children, offering seductive alternatives to the existential pursuit (Kessler 2000). Bakan (2004) claims that advertisements do not simply convey information: they also emphasise and strengthen specific values, constantly encouraging the relation between happiness and consumption and successful 
lives and material goods.

For young people such as the students in our class, the negative effects of advertising and consumerism are even worse. According to Rossiter (in De Souza et al. 2006) freedom and individuality are adored and any signs of a value-laden life consisting of commitments, altruism, sacrifices and fidelity are notably absent. He (Rossiter) avers that students therefore might easily get the message that life can be experienced without certain values, commitments and sacrifices. However, only once these young people realise that irrespective of their countless efforts they can never be a replicate of the striking advertising models who seemingly set the ideals of attractiveness, beauty and prestige that most aspire to, they start to feel inadequate in relation to society’s expectations.

In the foreword to Rachel Kessler's (2000) book The Soul of Education, Parker Palmer mentions that, despite the amazements in terms of science and technology, the $20^{\text {th }}$ century might also be described as one of "thin soup" (Palmer in Kessler 2000, v). It was a century where humans suppressed their humanness and "thinned" their humanity by - "turning wisdom into information, community into consumerism, politics into manipulation and destiny into DNA” (Palmer in Kessler 2000, v). These processes started to "thin” teaching and learning too. Palmer mentions that the "educational soup" became so thin yet our thirst for authentic life connections deepened. In fact, the "educational soup" diluted to the point where, the last few years of the $20^{\text {th }}$ century, necessitated radical change in classroom practices and calls for educational reform amplified. I concur with Palmer that, even though academic standards are important in education, the dilution of the "standards soup" have exacerbated to the extend where we are still experiencing its stark consequences: educators teaching to the test rather than preparing students for real life, and educators deliberately helping students to pass the test, knowing all too well that the aims and objectives can never be attained with the resources (or lack thereof) at hand (Palmer in Kessler 2000, vi).

In this article I wish to theoretically explore how the reawakening of spirituality through sense of place might address the thin educational soup that manifests as feelings of hopelessness in our youth. I will do this by firstly providing a brief background to why spirituality is needed in schools. Secondly, I will explore the notion of spirituality, followed by a discussion on the integration of spirituality and sense of place. Lastly, I will look at some of the implications for education.

\section{WHAT NECESSITATES THE RE-AWAKENING OF SPIRITUALITY IN FORMAL EDUCATION?}

Rossiter (in De Souza et al. 2006) states that adding to the problem of despair that students 
experience in a consumerist culture is the tendency of nihilistic thinking - the conviction that there is no meaning and purpose to life, which can coincide with a notably rational, materialistic and pragmatic view. He asserts that such a viewpoint (nihilistic thinking) can lead to high levels of depression, hopelessness, world-weariness, substance abuse and suicide, especially among the youth.

Furthermore, Bakan $(2004,120)$ claims that the culture of the marketplace can be labelled as a "virtual-reality" which is occupied by the advertising world, giving the consumer the power to rule and what is new is real. The media have also succeeded in cultivating the idea that the faster we produce or live, the faster we will reach the level of imaginary "satisfaction" that we all long for. Whilst the "fast life" has brought comfort, convenience and improvements at different levels, it has also conditioned us to think that faster is equal to better. Despite all the developments, improvements and comfort that science and technology have brought to human and non-human life, we cannot deny the fact that these have also estranged us from ourselves.

We have forgotten who and what we are without our mobile devices, latest trends and material wealth. The irony is that the things that claim to bring about improved and comfortable lifestyles are the exact same things that we often distance ourselves from when we experience a setback or suffering of any kind. For example, we tend to turn our mobile devices off and disconnect from the outside world when we have experienced a bad day. It is in these moments that we find solitude, along with answers to our deepest human needs, struggles and purpose in life. Yet, we are so busy living the fast life and keeping up with the latest trends that we often forget to feed our inner resources, which I refer to as our spirituality.

According to Kessler (2000), many students are deterred from their own search for meaning by the way meaning has been misrepresented through advertising. She claims that advertising strives to fill the void, yet it leaves students with nothing but a spiritual hunger. Kessler (2000) asserts that this spiritual hunger should be guided in profound ways for our youth to express their spiritual longing and purpose in life so as to approach adulthood with vitality and vision. Just as the physical body of the student will not grow if it is not properly nourished, the mind will not flourish unless it is stretched, and the spirit will suffer - even die if it is not nurtured (Kessler 2000). This indicates the necessity of educators (re)awakening the spirituality of students.

Palmer (1998) reminds us that, should we decide to embrace the spiritual dimension of education in our classes, we must take into consideration that spiritual inquiry and questions cannot be addressed in the way math problems do. He asserts the following: "When people ask deep questions they do not want to be saved, but simply to be heard, they do not want fixes or formulas but compassion ... on the demanding journey called life” (Palmer 1998, 8). Several 
people still consider the ultimate goal of education and schools to be cognitive development. However, any good and virtuous educator will agree that every student is a holistic assemblage uniquely constructed by emotions, thoughts, belief systems, family structures, culture, economics, spirituality - all of which directly impact a student's being, becoming and learning in the world. Schools and educators often focus more on the cognitive and academic development of students than on the spiritual. Many schools have excluded the spiritual dimension from education, and classrooms have become "spiritually empty".

One might reflect on why educators hardly embrace the big questions of students into the classroom. What are the effects on students when schools exclude and dismiss their pursuit for purpose, significance and meaning from the curriculum? According to Kessler (2000), many students cannot listen and focus attentively, nor feel motivated to learn. She asserts that it is the job of educators to assist these students in discovering their own quest for meaning in life. In many instances, subjects such as Life Skills/Orientation with Religious Education (RE) as vehicle are viewed as pathways to address feelings of hopelessness, demotivation and inadequacy among students. Against this background, the question arises: To what extent does RE in Life Skills/Orientation respond to such scenarios? This can be followed by a second question: Why can the reawakening of spirituality through sense of place be considered a more profound approach to address feelings of hopelessness, demotivation and inadequacy among students? I address the first question next.

\section{RELIGIOUS EDUCATION IN SOUTH AFRICAN PUBLIC SCHOOLS}

Ten values derived from the Constitution of South Africa that should be taught in the classroom are proposed in the Manifesto on Values, Education and Democracy. These are "Democracy, Social Justice, Equality, Non-racism and Non-sexism, Ubuntu (Human Dignity), An Open Society, Accountability (Responsibility), The Rule of Law, Respect, and Reconciliation” (Asmal 2001, 3). RE was introduced as one of sixteen strategies with which to attain these ten values. According to the Manifesto, RE in schools would

\footnotetext{
"provide the scope for learners to explore the diversity of religions that impel and inspire society, and the morality and values that underpin them. In this way, RE can reaffirm the values of diversity, tolerance, respect, justice, compassion and commitment in young South Africans” (Asmal 2001, 5).
}

As an avenue for promoting respect for difference and diversity among students, the South African policy on religion and education (DoE 2003) aims to highlight the importance of religion in teaching and learning in public schools. Through the subject Life Orientation the 
policy strives to advance diversity via religious education. Although a National Policy on Religion and Education has been promulgated as a means to embrace religious diversity in South Africa (DoE 2003, 8), Roux (2009) claims that there has been reluctance to implement this policy. The policy offers an explanation of the relationship between diversity and RE that will strengthen democracy by valuing diversity.

Regarding the Curriculum Assessment Policy Statement (CAPS), RE is located in the area "Personal and Social Well-being" in the learning programme Life Skills for the foundation phase (DoBE 2011, 10 and 31), and in Life Orientation in the senior phase (Faller and McCormick 2013, 3). The subject Life Skills "is aimed at guiding and preparing learners for life and its possibilities, including equipping learners for meaningful and successful living in a rapidly changing and transforming society” (DoBE 2011, 9). The area Personal and Social Well-being should enable learners to "show tolerance for ... religious diversity in order to contribute to a democratic society” (DoBE 2011, 10).

From this it is evident that the emphasis in RE is on learning about and respecting diverse religions, with the aim of democratic nation building in a post-apartheid dispensation. The classroom was seen as a powerful platform to enhance this process.

This proves to be a rather limited and technical view of RE, where the latter is regarded more as a vehicle to achieve the goals of the state than to bring about authentic personal change in each student. Empirical realities, such as the events of 11 September 2001, the Iranian revolution (Salvatore and Eickelman 2004, xiv), the solidarity movement in Poland, liberation theology in Latin America, as well as Protestant fundamentalism in the USA, usually bring RE under great scrutiny. Is it therefore enough to only learn about different religions and cultures in school? Is RE a sufficient strategy for addressing the values set out in our Constitution? If it is, how do we declare these stark realities? Should we not search for a deeper, transcendent and more profound avenue?

\section{EXPLORING THE MULTIDIMENSIONALITY OF SPIRITUALITY}

Although the concept of spirituality can be traced back to almost two thousand years to St. Paul, Kale (2004) affirms that it has only become a topic of systematic enquiry in recent years within the Social Sciences. Erricker (in De Souza et al. 2006) mentions that spiritual education is often confused or used interchangeably with religious education, because most can't imagine the "spiritual” as distinct from the "religious". According to Zakrzewski $(2013,1)$ spirituality is generally viewed as the: "beliefs, practices and experiences that shape and create a way of knowing and living that may or may not be informed by religious ritual, tradition and doctrine”. She further claims that a person is most likely to inherit religion, but consciously decides to 
become spiritually inclined by seeking answers about the self, universe and meaning of life (Zakrzewski 2013, 1). Scholars such as Farmer (2001), Miller (2001), Scherer (1999), Sefa (1999) and Wilson (1991) hold the view that the recent openness to spiritual development in the field of education is a response to current family and social ills, obsessive materialism, depression, alcohol and drug addiction, racism and wars.

Many regard the concept of spirituality as ambiguous. Various cultures define it based on their practices and preferences. Trousdale (in De Souza et al. 2006, 1226) defines spirituality as "a search of God", or a "God-directed focus", and "a naturalistic way of relating with the world”. She expounds that spirituality derives from the answers each individual, religion and culture can find by engaging with those similar questions our predecessors have asked: "Who am I? Is there a power beyond what I see, and if so, what is it like? What is my relationship with others and with creation to be?” (Trousdale in De Souza et al. 2006, 1225). Myers (1990, 11) defines spirituality as a "continuous search for meaning and purpose in life, an appreciation for the depth of life, the expanse of the universe, and natural forces which operate; a personal belief system.” According to Reich $(2000,126)$, spirituality is a "sharing of joy and sorrow and the deep connections made between human beings, between them and nature, and between them and a higher being.”

I do not wish to address the concept of spirituality within a religious realm, but rather within the existential frameworks of spirituality according to Webster (2004) and Kessler (2000). Webster (2004, 10-16) presupposes some attributes of spirituality that relate to how I use the term in this article:

Inwardness (subjectivity), that is an "awareness on the part of the individual that one's existence is in one's thinking and that this thinking only belongs to oneself" (Webster 2004, 10). Inwardness in this regard is not only concerned with looking inwardly, but more with how one relates to what one believes and understand; Relation, that is spirituality is not concerned with investigating whether "beings, deities, ideas or beliefs" (Webster 2004, 10) exist, but rather with how the individual relates to them. This also refers to a being that cannot disconnect from the relation that he or she has with the social and physical environments (Webster 2004, 11). Balance should be maintained between freedom of choice and culture, this implies that the individual is capable of finding and choosing his own answers to the most fundamental questions regarding the meaning of existence, and realising that "personal inner truth doesn't exist in a detached way from the world; it is historically and culturally embedded" (Webster 2004, 14); finally, Holistic perspective - concerns one's spirituality that includes the commitment of one's entire being, incorporating not only one's rationality, but also intentions, actions and emotions - one's whole presence in the world. 
Moreover, Kessler (2000, 17) advocates inviting soul/spirit back into education and, to this end, identified seven gateways through which spirituality can be addressed:

1) The longing for a deep connection involves the quality of a relationship that is deeply caring and embedded with meaning and feelings of belonging. Deep connections might be experienced to the self, to the other, to nature, or to a higher power. 2) The longing for silence and solitude can be described as a "realm of reflection", of "calm and fertile chaos", a path of stillness and rest for some, contemplation, meditation or prayer for others (Kessler 2000, 17). 3) The search for meaning and purpose has to do with the exploration of fundamental questions, such as "Why am I here?" "Does my life have a purpose?" "What is life for?” "Is there a God?" (Kessler 2000, 17). 4) The hunger for joy and delight can be attended to by means of play, festivities, relaxation or gratitude. It also entails the admiration students have when encountering beauty, grace, awe, love, mystery and power. 5) The creative drive is probably the most popular domain and is related to all the gateways - whether it involves generating new ideas, artwork or a completely new perspective on life, students feel the mystery and awe of creating. 6) The longing for transcendence relates to the urge among students to surpass their perceived limits. It concerns the mystical realm, and experiences of the arts, aesthetics, academics or social relations (Kessler 2000, 17). 7) The need for initiation has to do with rites of passage for the young - guiding students in becoming more conscious of the change from childhood to adulthood.

Based on the above, some scholars might argue that RE in schools also addresses these aspects. I argue that spiritual education (SE) transcends RE. Whereas RE has an institutional connotation that translates into adhering to dogmas and attending services and performing rituals, SE incorporates a transcendent realm within human experience. Within this realm, the individual not only questions the nature of existence but also strives to place the self in a larger ontological framework. Hughes (in De Souza et al. 2006) claims that RE in schools fails to address the students' own spirituality at the level of content. He claims that RE content is often about other people and religions thus failing at offering much to the young person who is in search of finding the purpose of his/her own existence. Hughes (in De Souza et al. 2006) furthermore avers that, if the content is always about people sharing a collective viewpoint based on metaphysical constructs that have no relevance in the student's own world, then the subject RE will not be effective and will remain boring and irrelevant.

In his critique of education, holistic educator Ron Miller $(1995,125)$ states: “Our culture does not nourish that which is best or noblest in the human spirit. It does not encourage gentleness, generosity, caring or compassion." Late in the twentieth century, the static, economic-technocratic, worldview has become an atrocious destructive force of that which is 
loving and life-sustaining in the human soul (Miller 1995, 125). Miller $(1995,125)$ asserts that "spirituality is nourished, not through formal rituals that students practice in school, but by the quality of a relationship that is developed between person and world”. Seen in this light, sense of place is crucial in (re)awakening spirituality.

A deepened spiritual connection is therefore needed for students to realise that the highest aspirations of the human spirit entails more than just collecting goods from a supermarket. According to Kessler (2000) a few people define the connection to the self as the foundation of spirituality, from which all other connections flow.

It is the responsibility of schools, educators, parents and the education system as a whole to re-direct students' attention to the spiritual dimension of life and to assist them in becoming more conscious of the negative effects of consumerism on the environment, and more so on themselves. This implies that educators need to alert students to personal qualities such as selfknowledge, self-possession, self-transcendence, love, openness and humility. Hart (in De Souza et al. 2006, 1150) affirms that, "when the inner life is attended to on a daily basis, it does not breed narcissistic preoccupation or indulgence, but rather the opportunity for depth”. This inward awareness provide balance between the centres of our individual depth with a more universal depth. Hart captures this neatly: "The universe lies not only about us but also within us; the outside can reveal the inside vice versa” (Hart in De Souza et al. 2006, 1152). In the following sections I introduce sense of place, preceded by a brief discussion of the notion of place, as it remains a fundamental concept in sense of place.

\section{"PLACE" IN SENSE OF PLACE}

Pedagogies of place are supportive educational traditions to help students (re)connect with the land and self (Greenwood 2013). It is important to note that central to all place theories/pedagogies is the student's sense of place. Using place as a starting point in reawakening spirituality will enable students to discover/recover/reconstruct the self in relation to place. Through a pedagogy of place, students will realise that places themselves have something to say and that it is our responsibility to listen attentively to the dominant stories of the place. Yet Greenwood $(2013,98)$ cautions that we need to devote attention not only to the latter narratives, but to "all the stories at risk of being silenced or erased, including the voice of the land itself” (see Ontong and Le Grange (2015a) for a more detailed discussion on this). It is the discovering/recovering/reconstructing of the self in relation to place that relates to sense of place. 


\section{(RE)AWAKENING SPIRITUALITY THROUGH SENSE OF PLACE}

A sense of place is essential in developing an affective connection with the place and/or land and to establish a conscious and responsible citizenry. Resor (2010) claims that sense of place is the key concept that needs to be thoroughly understood when practising a pedagogy of place. According to Ardoin (2006), sense of place is a holistic concept which includes the psychological, social, cultural, biophysical, political and economic systems. It is only when we start acknowledging the interrelationship between these dimensions that sense of place as a multidimensional and integrated concept is understood (Resor 2010). However, just like spirituality, sense of place is not something that we consider on a daily basis. Orr $(1992,126)$ describes this as "the ease with which we miss the immediate and mundane" (see Ontong and Le Grange (2015a; 2015b) for more in this regard).

Stedman (2003) and Trentelman (2009) claim that the biophysical characteristics of place refer to the landscape as well as the plant and animal species that interact within the ecosystem and form the fundamental components of sense of place. The sociocultural dimension, such as the cultural practices and demographic conditions, builds on the "community attachment" construct (Brehm, Eisenhauer, and Krannich 2006). The psychological dimension involves those internal attributes of a person and his/hers relationship to place, for example a feeling of "belonging somewhere” (Ardoin, Schuh, and Gould 2012, 585). And lastly, the politicaleconomic dimension concerns employment opportunities, finances, and politics (Ardoin 2006; Ardoin, Schuh, and Gould 2012).

At this stage the question arises: How does sense of place relate to (1) the attributes of spirituality according to Webster (2004), and (2) the seven gateways of spirituality as explained by Kessler (2000)? In the following section, I will try to provide an integrated discussion of how the four dimensions of sense of place could relate to Webster's (2004) and Kessler's (2000) explorations of spirituality. It is important to consider the fluidity of the attributes and gateways and to keep in mind that these dimensions do overlap at times.

Forming the basis from which all other dimensions flow, the biophysical dimension of sense of place (the landscape and non-human world) encompasses all the attributes and gateways of spirituality presupposed by Webster (2004) and Kessler (2000). In order to understand the biophysical world and how the individual relates to it, one first has to understand one's own being in the world. Therefore, a return inwardly is needed in an attempt to apprehend the source of one's values and actions. In the process of apprehending how one relates to certain things/people/the biophysical world, it is important to maintain a healthy balance between “objective cosmological world-views” and "subjective personal meanings” (Webster 2004, 11). The culturally embedded individual should bear in mind that although society might seem to 
have certain answers to most fundamental questions, he/she still has agency to choose the answers for him/herself.

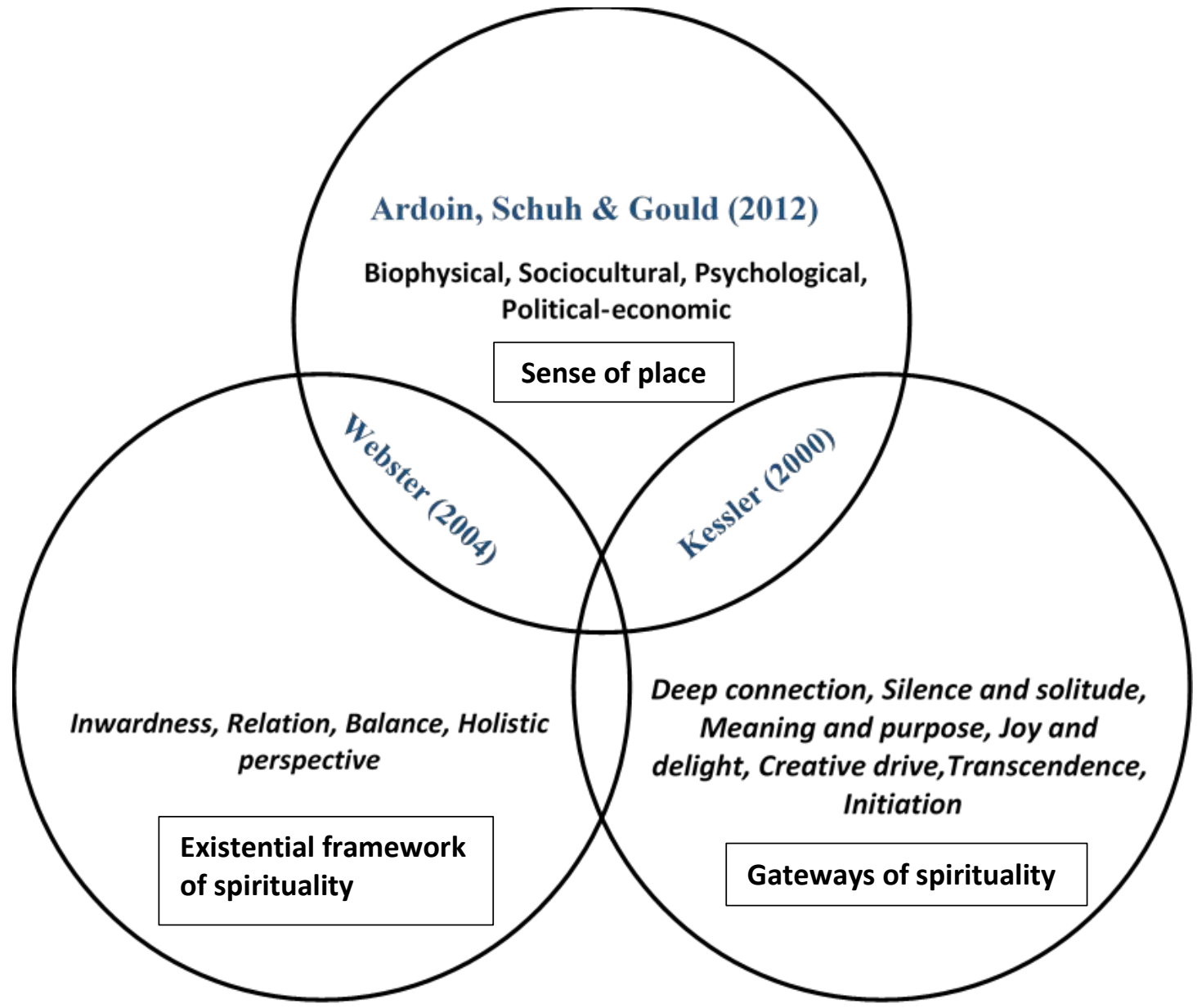

Figure 1: The integration of spirituality and sense of place.

The biophysical dimension of sense of place creates a platform from which one can see this embeddedness and interconnectedness with the physical and non-physical world - thus incorporating Webster's (2004) attribute of holism. In the process of comprehending the significance of meanings that give sense to one's particular experiences, one responds holistically by forming views and commitments that incorporate more than just rational or intellectual knowing (Webster 2004). Serving as a multidimensional concept, sense of place involves the human being as a whole and relates to the notion of holism.

Likewise, the biophysical dimension can also be linked to the fourth gateway of spirituality advocated by Kessler (2000), namely the hunger for joy and delight. This gateway entails the feelings one experience when encountering beauty, awe, power, grace and sheer joy. The biophysical dimension creates the space where the individual can deeply (re)connect to and experience life's mystical forces. Encounters like these not only bring us to a higher level of 
solitude, but also enable us to hear the quiet whispers of our soul. As Stables $(2002,6)$ reminds us "that many of our most fulfilling experiences are encounters with the non-human - often when we are alone." He expounds: "We remember such things because they either disrupt, question or make us somehow aware of our frames [of mind] and remind us that there is always life beyond the narrow limits of our reason: life to which we are related in some way, though we cannot understand it” (Stables 2002, 6).

The sociocultural dimension (e.g. cultural practices, community attachment) of sense of place relates to the attributes of both relation and balance (Webster 2004) as explained above. It also speaks to the first and third gateways of Kessler (2000) namely deep connection and the search for meaning and purpose. The latter involves the need for students to ask deep questions of what their purpose on earth is and how it fits into the bigger picture for example: "Who am I?” “What am I?” "What is my being?” "What is the meaning of being?” and "How do I relate to the social and cultural world, that is, my place and community?” (Webster 2004, 11-13). However, in the search for answers to these questions, one should remember that the individual does not exist in a detached way from the world and that inner truth does not emerge independently from being-in-the-world. In order to strengthen the socio-cultural dimension, educators should create opportunities for profound encounters with people from various cultures and religions. By doing this, a sense of wholeness and interconnectedness of self with the social is felt. In such experiences students subconsciously “come into presence” through the power and subtlety of otherness. The socio-cultural dimension not only helps in reflecting on one's attachment to and ties with communities but also makes one realise that even though one might be influenced and affected by society and the embedded relations, one is not determined by them.

The psychological being of "sense of place", such as the feelings of belonging, can be linked to both the attributes of relation and holism as explained by Webster (2004). As historically and culturally embedded beings the individual yearns for deep connection Kessler's (2000) first gateway. This gateway concerns the feelings of belongings to the self, others, nature and a higher power. Such yearnings add meaning and purpose to our existence. Here Webster's inwardness comes into play again, in terms of which he explains that one (in this case the students) should first raise awareness that existence is in one's thinking, which belongs to oneself, and that each existence is unique and significant. If one changes your fundamental thinking, you change your existence (Webster 2004). In order to reach this level one has to experience silence and solitude, which relate to the second gateway of Kessler (2000). In this sense, silence serves as a realm of reflection for the individual. If it happens that one notes dissatisfaction in terms of one's existence, an urge for transcendence could arise - 
the sixth gateway of Kessler. Educators therefore should help students to channel this powerful urge by going beyond their perceived limits.

According to Ardoin, Schuh, and Gould (2012), the political-economic dimension (job opportunities, finances, political borders) is the least developed in the empirical literature on place. Based on the above discussion, this dimension could relate to inwardness and holism defined by Webster (2004). As mentioned earlier, inwardness is needed to understand one's existence in relation to self and other things. As this search continues, it becomes easier to critically study the places one inhabits. This suggests uncovering the political-economic powers that are entrenched in places and how they constrain/control one's existence. This dimension enables students to realise that they are part of the larger political and economic forces and that their decisions and actions are directly linked. The political-economic dimension also enables them to think of their own existence in terms of the occupations and careers they want to pursue that would bring about material prosperity in their lives. It therefore involves a holistic perspective from which students need to think deeply about their existence, relations and purpose in life, where they want to be, where they currently are and what the conscious actions are that they should take now in order to get where they want to be in terms of financial and material prosperity.

This dimension also links to the fifth and seventh gateways stipulated by Kessler (2000), namely the creative drive and the need for initiation. The gateway of creativity concerns the development of a new idea or an entirely new lens on life. The educator should assist students as the need for initiation in terms of decision-making and action arises. This can be done by asking critical questions that assist students in transitioning from childhood to adulthood. By providing mechanisms for dealing with all of life's transitions, the educator takes on the role of a counsellor, life coach and source of motivation.

\section{IMPLICATIONS FOR EDUCATION}

The above discussion implies that, as educators, we need to start by first exploring our own spirituality and sense of place. We need to be concerned with how we comprehend the world and our relations in it at a fundamental level. Perhaps a question to consider is: How do we or how should we relate to (spiritual) education in a post-human era? This prompts some other key questions: What should be the underlying spirit or attitude towards the world in this age? What kinds of knowing and learning should education encourage? I concur with Bonnett (2003) that we need to explore the possibility of a different metaphysical basis for education. Although there are no fixed steps or a one-size-fits-all approach, there are certain considerations that educators could bear in mind when practising pedagogies of place as a means to spiritual 
reawakening. One way forward is to acknowledge that the student is a physical, rational, emotional, social and spiritual human being. This should be addressed and reflected in all learning programmes, curriculum design and pedagogies. Therefore, the important role of spirituality in education should be revisited and readdressed. More importantly, this needs to happen at all levels in society from policy writers, government funding bodies to practitioners who are dealing with issues related to inadequacy, discontentment and undesirable social behaviour.

Considering a different metaphysics to education, educators could bear in mind the works of Rousseau (1894). In Emile, Rousseau (1894, 12-15) refers to three educators that educate humans: "Nature, things and man.” If humans want to experience harmony, all three educators must be synchronised. Based on the fact that humans cannot control Nature, and have limited control over things, the master educator must be Nature. Yet Rousseau (1894) claims that formal education and educators "educate the nature out of children” Rousseau $(1894,14)$. According to him, the most basic characteristic of nature is "self-preservation (amour de soi) and compassion (pitiê)” Rousseau $(1894,13)$.

The scope of this article does not permit a discussion of these characteristics in detail, but they are used as a point of reference in Peckover's (2012) argument. As discussed earlier, one of the seven gateways to spirituality is the creative drive. According to Kessler (2000), this gateway is the most familiar one for nurturing the spirit in school and relates to all the gateways. According to Peckover, this is not catered for in formal education. He claims that, by divorcing the child from his or her own creative needs and defining the learning process as schooling, "education becomes a wedge between the student and his or her self-realisation" (Peckover 2012, 88). Hung (2008) avers that this tendency has been perpetuated throughout the schooling process and remains dominant in the current system of education. This type of education tend to "alienate children from their natural self and civilise them for social reproduction" (Peckover (2012, 88). As further stated by Peckover $(2012,88)$ "it ensures predictability and reinforces a fear of the deviant or unknown”.

Adding to this are the notions of standardisation and performativity, which, according to Rousseau (1894), only enable humans to buy “imaginary ease”, at the expense of real happiness. Standardising the education system around economic success, limit the opportunities for students to explore the natural (biophysical) environment and threaten the chances of experiencing deep connections with the self, others and place. The school environment itself is separated from the natural environment by walls, doors, windows and shades. Students are restricted by windows from experiencing the natural environment and can only view what is “out there”, but not necessarily experience it (Peckover 2012). 
Rousseau (1894) suggests that for humans to experience quality education, they should avoid interfering with Nature's way and instead participate in it. As educators we have to create more opportunities for students to discover and explore their natural interests by incorporating their sense of place and spirituality into pedagogy. If we do not, conflict will arise between that which a student is naturally attracted to and what society pressures the student into - thus resulting in conflict between the three educators - Nature, man and things (Peckover 2012). This type of conflict conjures up the negative feelings caused by consumerism and advertising.

Practices that can help both students and educators to (1) connect to their internal world and (2) create balance with the desires and needs of their external world needs to be developed. This might be useful in promoting acceptance of the self and other and encourage a sense of place but more importantly a sense of presence in the world.

Educators might want to consider alternative conducive spaces for reawakening the spirituality of students such as the natural environment, the outdoors and local neighbourhoods. A pedagogy of place emphasises the natural environment for teaching and learning. In this way the natural environment itself, becomes the curriculum. In selecting a conducive space for formal instruction, it is important to remember that, for some students, it is the beauty and majesty of nature that calls forth the awe and wonder to satisfy the spirit. For others, it is the power and mystery that defy human control and put everyday problems or disappointments into perspective.

\section{CONCLUSIONS}

In this article I have tried to demonstrate how the negative feelings caused by consumerism and advertising can be addressed by reawakening the spirituality of students through sense of place. In doing so, perhaps it would be useful to remember the profound words of Thomas Moore (1992, 223):

\footnotetext{
"Soul/spirit is at home in a sense of time that reaches beyond the limits of ordinary human life ... the soul/spirit is interested in the eternal issues, even as it is embedded in the particulars of ordinary life. It's not important where you think the soul is; it's what you're looking for with it, that's important.”
}

\section{REFERENCES}

Ardoin, N. M. 2006. Toward an interdisciplinary understanding of place: Lessons for environmental education. Canadian Journal of Environmental Education 11: 112-126.

Ardoin, N. M., J. S. Schuh and R. S. Gould. 2012. Exploring the dimensions of place: A confirmatory factor analysis of data from three ecoregional sites. Environmental Education Research 18(5): 583-607.

Asmal, K. 2001. Minister's Foreword on the Manifesto on Values, Education and Democracy. 
http://www.dhet.gov.za/Reports\%20Doc\%20Library/Manifesto\%20on\%20Values,\%20Educatio n\%20and\%20Democracy.pdf (Accessed 31 July 2017).

Bakan, J. 2004. The corporation: The pathological pursuit of power. The Free Press, 119-122.

Bonnett, M. 2003. Education for sustainable development: Sustainability as a frame of mind. Journal of Philosophy of Education 37: 675-690.

Brehm, J. M., B. W. Eisenhauer and R. S. Krannich. 2006. Community attachments as predictors of local environmental concern: The case for multiple dimensions of attachment. American Behavioral Scientist 50(2): 142-165.

De Klerk-Luttig, J. 2008. Spirituality in the workplace: A reality for South-African educators? SouthAfrican Journal of Education 28: 505-517.

Department of Basic Education. 2011. Curriculum and Assessment Policy Statement (CAPS) Life Skills - Foundation Phase. Pretoria: Department of Basic Education.

Department of Education. 2003. National Policy on Religion and Education. Pretoria: Government Gazette 459, 25459. 12 September 2017.

DoBE see Department of Basic Education.

DoE see Department of Education.

Dwyer, R. E. 2007. Expanding homes and increasing inequalities: US housing development and the residential segregation of the affluent. Social Problems 54: 23-46.

Erricker, C. 2006. Religious education and spiritual development: Pedagogical insufficiency and possibility. In International handbook of the religious, moral and spiritual dimensions in education, ed. M. de Souza, G. Durka, K. Engebretson, R. Jackson and A. McGrady, 697-715. The Netherlands: Springer.

Faller, P. and J. McCormick 2013. Curriculum and Assessment Policy Statement (CAPS) Life Orientation for Further Education and Training (FET) - Grade 10-12. http://www.cso.za.org/ 2013_RE_CAPS_CORD_(Gr_10-12).pdf. (Accessed 30 October 2017).

Farmer, D. 2001. The biospiritual awakening? Public Performance and Management Review 24(4): 436-439.

Greenwood, D. A. 2013. A critical Theory of place-conscious education. In The international handbook of research on environmental education, ed. R. B. Stevenson, M. Brody, J. Dillon and A. E. J. Wals, 93-100. New York: Routledge.

Hart, T. 2006. Transforming self and subject: Toward an integrative spiritual pedagogy. In International handbook of the religious, moral and spiritual dimensions in education, ed. M. de Souza, G. Durka, K. Engebretson, R. Jackson and A. McGrady, 1149-1165.The Netherlands: Springer.

Hughes, P. 2006. The future of religious education in the context of postmodernity. In International handbook of the religious, moral and spiritual dimensions in education, ed. by M. de Souza, G. Durka, K. Engebretson, R. Jackson and A. McGrady, 349-361. The Netherlands: Springer.

Hung, R. 2008. Educating for and through nature: A Merleau-Pontian approach. Studies in Philosophy and Education 27(5): 335-367.

Kale, S. H. 2004. Spirituality, religion, and globalization. Journal of Macromarketing 24(2): 92-107.

Kessler, R. 2000. The soul of education. Virgina, USA: ASCD (Association for Supervision and Curriculum Development).

Little, A. 2000. Development studies and comparative education: Context, content, comparison and contributors. Comparative Education 36(3): 279-296.

Miller, D. 2001. Programs in social work embrace the teaching of spirituality. The Chronicle of Higher Education 47(3): A12-A13.

Miller, Ron. 1995. Educational freedom for a democratic society: A critique of national educational goals, standards, and curriculum. Brandon, VT: Resource Center for Redesigning Education.

Moore, T. 1992. Care of the soul: A guide for cultivating depth and sacredness in everyday life. New 
York: HarperCollins.

Myers, J. E. 1990. Wellness throughout the lifespan. Guidepost 11.

Ontong, K. and L. le Grange. 2015a. The role of place-based education in developing sustainability as a frame of mind. Southern Journal of Environmental Education 30: 27-38.

Ontong, K. and L. le Grange. 2015b. The need for place-based education in South-African schools: The case of Greenfields Primary. Perspectives in Education 33(3): 5-20.

Orr, D. 1992. Ecological literacy: Education and the transition to a postmodern world. Albany, N.Y.: State University of New York Press.

Palmer, P. 1998. The courage to teach: Exploring the inner landscape of a educator's life. San Francisco: Jossey-Bass.

Peckover, C. 2012. Realising the natural self: Rousseau and the current system of education. Philosophical Studies in Education 43: 84-94.

Reich, K. H. 2000. What characterizes spirituality? A comment on Pargament, Emmons and Crumpler, and Stifoss-Hansen. International Journal for the Psychology of Religion 10(2): 125-128.

Resor, C. W. 2010. Place-based education: What is its place in the social studies classroom? The Social Studies 101: 185-188.

Rossiter, G. 2006. The spiritual and moral dimension to school curriculum: A perspective on across-thecurriculum studies. In International handbook of the religious, moral and spiritual dimensions in education, ed. by M. de Souza, G. Durka, K. Engebretson, R. Jackson and A. McGrady, 679-696. The Netherlands: Springer.

Rousseau, J. J. 1894. Emile or concerning education. Translated by Eleanor Worthington. Boston: D.C. Heath \& Company.

Roux, C. 2009. Religion in education: Who is responsible? Alternation 3(Special Edition): 3-30.

Salvatore, A. and D. F. Eickelman. (Eds.). 2004. Public Islam and the common good. Leiden: Brill.

Scherer, M. 1999. Is school the place for spirituality? Educational Leadership 56(4): 18-22.

Sefa, G. 1999. Knowledge and politics of social change. The implication of antiracism. British Journal of Sociology and Education 20(3): 395-409.

Stables, A. 2002. On the making and breaking of frames in pursuit of sustainability. The Trumpeter 18: $1-10$.

Stedman, R. C. 2003. Sense of place and forest science: Toward a program of quantitative research. Forest Science 49(6): 1-8.

Stromquist, N. P. and A. Monkman. 2000. Globalisation and education: Integration and contestation across cultures. Maryland: Rowman \& Littlefield Publishes Inc.

Trentelman, C. 2009. Place attachment and community attachment: A primer grounded in the lived experience of a community sociologist. Society and Natural Resources 22: 191-210.

Trousdale, A. M. 2006. The role of literature in children's spiritual development. In International handbook of the religious, moral and spiritual dimensions in education, ed. by M. de Souza, G. Durka, K. Engebretson, R. Jackson and A. McGrady, 1225-1235. The Netherlands: Springer.

Webster, R. S. 2004. An existential framework of spirituality. International Journal of Children's Spirituality 9(1): 7-19.

Wilson, B. 1991. Religion in sociological perspective. Oxford: Oxford University Press.

Zakrzewski, V. 2013. The case of discussing spirituality in schools. https://greatergood.berkeley.edu/ article/item/how_to_discuss_spirituality_in_school (Accessed 2 December 2017). 